\title{
CDISC SDTM Implementation Guide Version 3.1.2
}

National Cancer Institute

\section{Source}

National Cancer Institute. CDISC SDTM Implementation Guide Version 3.1.2. NCI

Thesaurus. Code C161433.

The 3.1.2 version of the CDISC Study Data Tabulation Model (SDT M) implementation guide. 